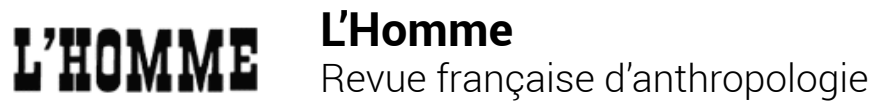

160 | octobre-décembre 2001

Droit, coutume, mémoire

\section{Sara Le Menestrel, La Voie des Cadiens. Tourisme et identité en Louisiane}

Paris, Belin, 1999, 431 p., bibl., annexes, index, ill.

\section{Caroline Legrand}

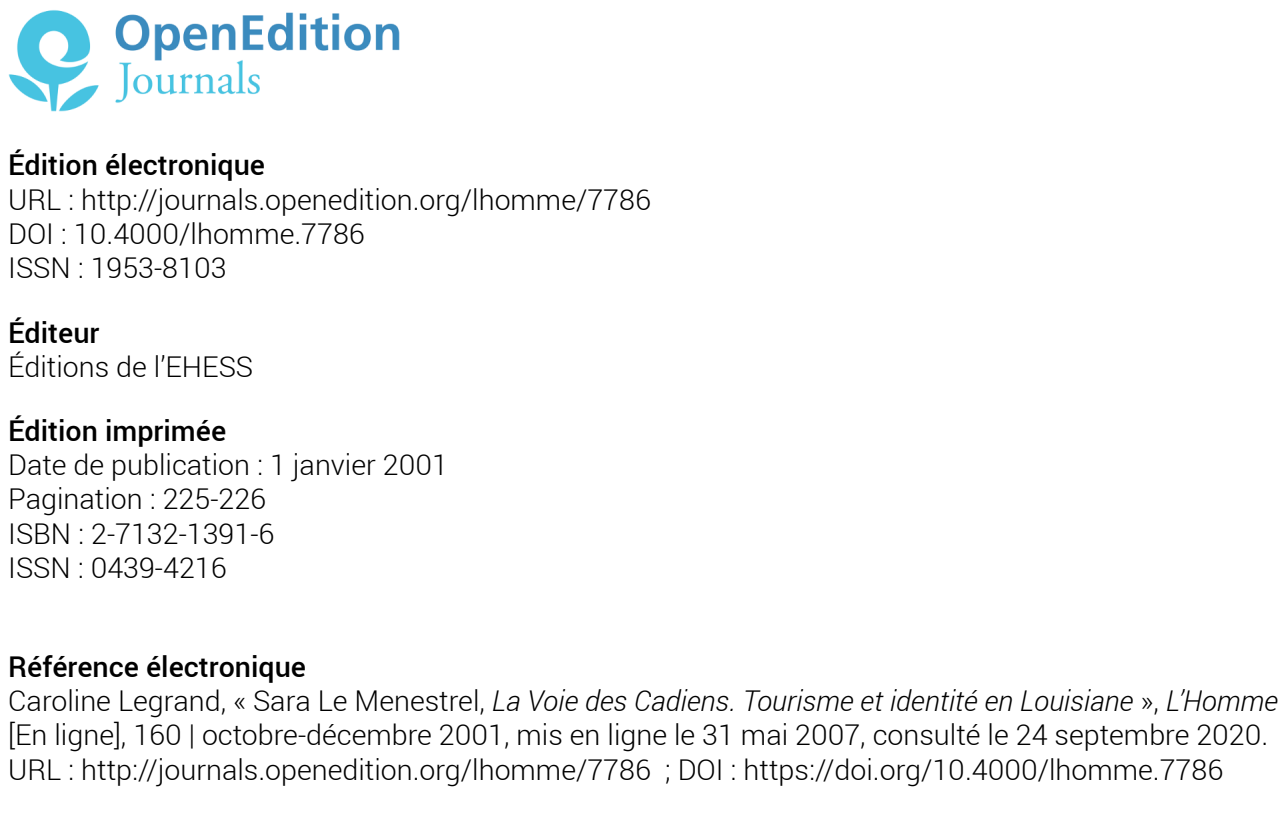

Ce document a été généré automatiquement le 24 septembre 2020.

(c) École des hautes études en sciences sociales 


\section{Sara Le Menestrel, La Voie des Cadiens. Tourisme et identité en Louisiane}

Paris, Belin, 1999, 431 p., bibl., annexes, index, ill.

\section{Caroline Legrand}

1 AU DÉBUT des années 1970, un certain nombre d'anthropologues se sont intéressés à l'activité touristique. Tandis que les uns ont cherché à identifier les motivations et les buts du touriste, d'autres se sont employés à décrire les conséquences unilatérales que pouvait entraîner la venue de milliers de vacanciers sur une société donnée, en insistant sur les transformations environnementales et culturelles que celle-ci subissait. Plus récemment, d'aucuns ont souligné le rôle actif des sociétés dites d'accueil sur l'expansion de l'activité touristique dans leur territoire. L'approche adoptée ici par Sara Le Menestrel s'inscrit dans cette dernière perspective.

2 L'auteur se penche sur une partie de la société louisianaise qui a fait du tourisme un moyen non seulement de diversifier ses ressources économiques, mais aussi de lui fournir de nouveaux référents identitaires. À l'aide d'un important corpus ethnographique, l'ethnologue nous fait découvrir deux communautés - celle des Cadiens et celle des Créoles - qu'elle a rencontrées entre 1994 et 1996 dans la région de La Fayette. Les premiers, installés en Louisiane depuis la déportation de leurs aïeuls à la fin du XVIII ${ }^{\mathrm{e}}$ siècle, sont les descendants de migrants Acadiens, tandis que les seconds sont d'ascendance noire. Cohabitant à l'intérieur d'un même espace, Cadiens et Créoles partagent la même religion. Catholiques, la plupart d'entre eux sont francophones, caractéristique qui constitue, comme le montre bien Sara Le Menestrel, un des principaux attraits touristiques du sud-est louisianais.

3 Particulièrement attentive aux processus modernes de construction de l'identité cadienne, l'auteur souligne cependant que peu de Cadiens parlaient encore le français au début $\mathrm{du} \mathrm{xx}^{\mathrm{e}}$ siècle. Source de nombreuses discriminations et obstacle à la réussite sociale, le français fut rapidement abandonné. C'est seulement récemment qu'une association cadienne militante, créée dans les années 1960, s'est donné pour objectif de 
promouvoir la culture et la langue françaises et de raviver localement l'usage de celleci. La mise en place de cette association est, selon Sara Le Menestrel, à l'origine du renouveau identitaire qui caractérise depuis Cadiens et Créoles, de sorte que ces deux groupes, autrefois dénigrés par les nativistes américains, sont aujourd'hui fiers de leurs origines. Leur engouement pour la quête généalogique et pour leur histoire collective, ainsi que le renforcement de leurs revendications identitaires en sont la preuve. La construction de cette identité positive apparaît directement liée à l'essor de l'activité touristique dans cet État qui, jusqu'à un passé récent, tirait ses principales ressources économiques de l'industrie pétrolière.

4 Pour inciter les touristes à visiter leur région, les Cadiens n'hésitent pas à mettre en avant son particularisme culturel, et cela est d'autant plus intéressant que la majorité des touristes qui s'y rendent sont américains. Se prévalant de leur hospitalité et de leur joie de vivre, les Cadiens en viennent à rire des tares (oisiveté et ignorance) qui leur étaient prêtées au début du siècle par les nativistes. Ils mettent en scène la destinée tragique de leurs ancêtres acadiens dans le cadre des nouveaux espaces muséographiques et s'approprient certains produits issus du multi-culturalisme local, comme le «gumbo», spécialité culinaire dont certains ingrédients sont importés de France et d'Afrique tandis que d'autres sont des produits locaux.

5 Par le riche contenu de ses enquêtes, Sara Le Menestrel contribue non seulement à l'étude anthropologique du phénomène touristique, mais aussi à celle des processus modernes de construction identitaire dans une communauté francophone des ÉtatsUnis jusque-là délaissée par les anthropologues. Son analyse est fine et son argumentation fort bien illustrée, notamment par des extraits d'entretiens. L'ouvrage, qui comporte une typologie des principaux informateurs, un tableau chronologique, un glossaire, un index ainsi qu'une importante bibliographie, se lit aisément en dépit de quelques longueurs et répétitions.

\section{AUTEUR}

CAROLINE LEGRAND

EHESS, Paris. 